\title{
FABRICATION AND TESTING FOR NANOSATELLITE
}

\section{DEPLOYABLE MECHANISMS}

\author{
R. PRAVEEN KUMAR ${ }^{1}$, P. MANIKANTA $^{2}$, MNVRL KUMAR $^{3} \&$ R. SANTHOSH KUMAR ${ }^{4}$ \\ ${ }^{I}$ Assistant Professor, Department of Mechanical Engineering, Lakireddy Bali Reddy \\ College of Engineering, Andhra Pradesh, India \\ ${ }^{2,3} \& 4$ Assistant Professor, Department of Mechanical Engineering, Koneru Lakshmaiah
}

Educational Foundation, Andhra Pradesh, India

\begin{abstract}
This paper deals with the deployable mechanisms of nanosatellite like an antenna, Cubesat deployer. A suitable communication antenna as per the CubeSat standard was considered for QB50. The design and deploying mechanism was modeled. A suitable mechanical design was incorporated to deploy the antennas once in orbit. Also, a CAD model of the Cubesat deployed for the Cubesat as per QB50 standards is modeled by using SOLIDWORKS soft. This CAD model is to be subjected to vibration analysis using ANSYS software to ensure that the CubeSat deployed could withstand the launching conditions. The FEA simulation analysis provides information on the performance of the CubeSat deployer at different static, dynamic and environments.

Keywords: Cubesat Deployer \& Vibration Analysis
\end{abstract}

Received: Mar 15, 2018; Accepted: Apr 05, 2018; Published: Apr 27, 2018; Paper Id.: IJMPERDJUN201815

\section{INTRODUCTION}

Cubesat is a type of miniaturized satellite for space research made up of multiples of $10 \times 10 \times 10 \mathrm{~cm}$ cubic units, has a mass of no more than 1.33 kilograms per unit, and often sees the use of commercial off-theshelf components for its electronics and structure. Cubesats are most commonly put in orbit by deploying on the International Space Station, or launched as secondary payloads on a launch vehicle.

The scope of this work is a modeling and fabrication of antenna deployment mechanism. Fabrication and testing of antenna deployment. Modeling of Cubesat deployer, Analysis of Cubesat deployed using FEM software.

\section{Deployable Mechanisms}

The need for deployable space structures has become increasingly evident in recent Years with the rise in small satellite launches, and the desire for higher performing, more Complex scientific studies performed with these satellites.

- Antenna deployment

- Solar panel deployment

- Cubesat deployment. 


\section{NANORACK CUBESAT DEPLOYER}

\section{Methodology}

The Nanoracks cubesat deployer(NRCSD) plays a critical role in as the interface between the launch vehicle and satellites . Then, Nanoracks Cubesat deployer (NRCSD is a standard deployment system, which will help in the effort to reduce the satellite development time for the CubeSat program. This standard deployed ensures all CubeSat developers conform to common physical requirements, which will reduce cost and development time. The Flowchart of the proposed methodology is shown in Figure 1.

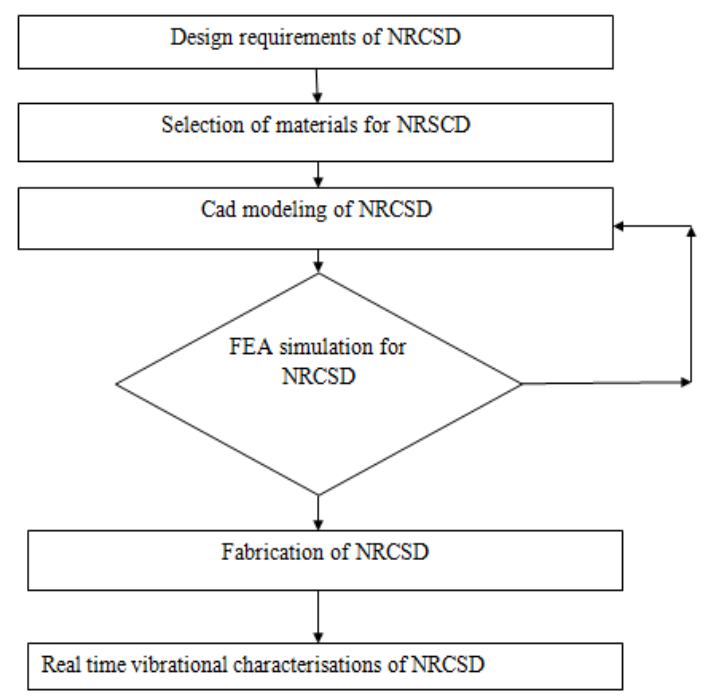

Figure 1: Methodology for Deployer

\section{Design Constraints}

The design constraints of the Cubesat deployed have been given by the QB50 system requirements. The various dimensions along each axis(x, y, and $\mathrm{z})$, the mass of the deployer are listed in Table 1.

Table 1: Dimensions of Cubesat Deployer

\begin{tabular}{|l|c|}
\hline \multicolumn{1}{|c|}{ Dimension } & 2U Deployer \\
\hline Length*width $(\mathrm{mm} * \mathrm{~mm})$ & $132 * 168$ \\
\hline Height $(\mathrm{mm})$ & 860 \\
\hline Mass $(\mathrm{kg})$ & 1.75 \\
\hline
\end{tabular}

\section{ANTENNA DEPLOYMENT SYSTEM}

\section{Methodology}

Communication plays a vital role in satellites. Gamma et antenna is collection different types of antennas in the satellite. Communication takes place between satellite to satellite and satellite to a ground station. The Flowchart of the proposed methodology is shown in Figure 2. 


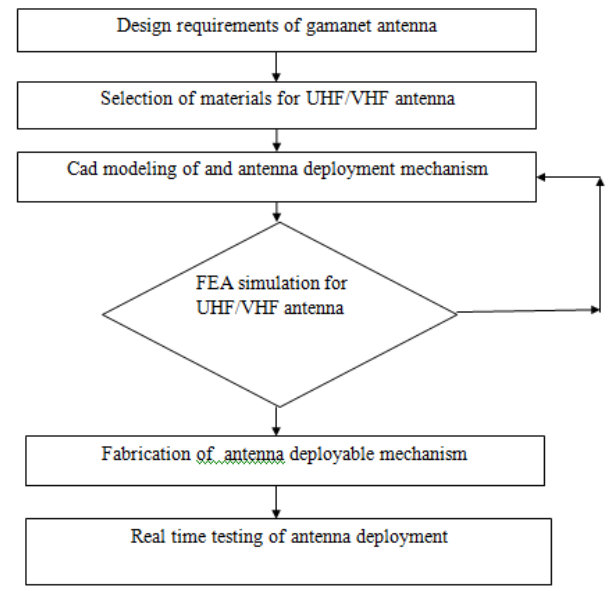

Figure 2: Methodology for Antenna Deployable Mechanism

\section{Design Configuration}

The configurations of the 2U Cubesat structure have been given by the QB50 system requirements. The various dimensions along each axis( $\mathrm{x}, \mathrm{y}$, and $\mathrm{z})$, the thickness of the rail and its feet were listed in Table 2

Table 2: Design Constraints of Communication System

\begin{tabular}{|l|l|l|}
\hline & \multicolumn{1}{|c|}{ Advanced Mode } & \multicolumn{1}{c|}{ Compatibility Mode } \\
\hline $\begin{array}{l}\text { Frequency: Downlink } \\
\text { Uplink }\end{array}$ & S-band $(2.40-2.45 \mathrm{GHz})$ & $\begin{array}{l}\text { UHF }(430-440 \mathrm{MHz}) \\
\text { VHF }(144-148 \mathrm{MHz}\end{array}$ \\
\hline $\begin{array}{l}\text { Bandwidth: Downlink } \\
\text { Uplink }\end{array}$ & $40 \mathrm{MHz}$ & $\begin{array}{l}20 \mathrm{kHz} \\
10 \mathrm{kHz}\end{array}$ \\
\hline $\begin{array}{l}\text { Data Rate: Downlink } \\
\text { Uplink }\end{array}$ & up to $1 \mathrm{Mbit} / \mathrm{s}$ & $\begin{array}{l}9600 \mathrm{bps} \\
1200 \mathrm{bps}\end{array}$ \\
\hline $\begin{array}{l}\text { Antennas: } \\
\text { 3-axis stabilized } \\
\text { Spinning }\end{array}$ & $\begin{array}{l}\text { 4 }(3 \mathrm{~S}-\text { band }+1 \mathrm{GPS}) \\
10(6 \mathrm{~S}-\text { band }+4 \mathrm{GPS})\end{array}$ & To be defined by Teams \\
\hline Antenna size: & Other combinations possible & \\
S-Band Patch & approx. $25 \times 25(\mathrm{~mm})$ standalone \\
S-Band monopole & approx. $25 \times 35(\mathrm{~mm})$ standalone \\
GPS Patch UHF/VHF & approx. $25 \times 25(\mathrm{~mm})$ standalone \\
\hline To be defined by Teams & \\
\hline Semply Voltage & $3.3 \mathrm{~V}$ \\
\hline
\end{tabular}

\section{SELECTION OF MATERIAL}

\section{Nanorack Cubesat Deployer}

In order to meet the mission requirements, many lightweight and durable materials are utilized in the cubesatellite structural design. Material strength is integral to the structural survival of the spacecraft. AA 7075 material is selected for the $2 \mathrm{U}$ Cubesat structure since it has a high stiffness to density ratio, excellent workability, non-magnetism, moderate cost, high ductility, high corrosion-resistance, and availability. AA7075 is a heat treatable; this alloy is the strongest and hardest aluminum alloy. It has good machining characteristics, but it is neither very easily welded nor very workable. The material composition and material properties of the AA 7075 were listed in Table 3 and Table 4. 
Table 3: Material Compositions

\begin{tabular}{|c|c|c|c|c|c|c|}
\hline ELEMENT & $\mathrm{Al}$ & $\mathrm{Zn}$ & $\mathrm{Mg}$ & $\mathrm{Cu}$ & $\mathrm{Fe}$ & $\mathrm{Cr}$ \\
\hline WEIGHT (\%) & 90.4 & 5.1 & 2.1 & 1.2 & 0.5 & 0.18 \\
\hline
\end{tabular}

Table 4: Material Properties

\begin{tabular}{|l|c|}
\hline \multicolumn{2}{|c|}{ Mechanical Properties at 250C } \\
\hline Density (kg/m3) & 2800 \\
\hline Poisson's Ratio & 0.33 \\
\hline Elastic Modulus (GPa) & 80 \\
\hline Tensile Strength (MPa) & 230 \\
\hline Yield Strength (MPa) & 105 \\
\hline Elongation (\%) & 17 \\
\hline Hardness (HB500) & 60 \\
\hline Shear Strength (MPa) & 150 \\
\hline Fatigue Strength (MPa) & 160 \\
\hline \multicolumn{2}{|c|}{ Thermal Properties } \\
\hline Thermal Expansion(10-6/0C) & 23.2 \\
\hline Thermal conductivity (W/m-K) & 130 \\
\hline Melting Point $\left({ }^{\circ} \mathrm{C}\right)$ & 582 \\
\hline
\end{tabular}

\section{Antenna Deployment System}

Material - 301spring tempered stainless steel.

Spring steel is a name given to a wide range of steels used widely in the manufacture of springs. These steels are generally low-alloy, medium-carbon steel or high-carbon steel with very high yield strength. This allows objects made of spring steel to return to their original shape despite significant deflection or twisting. The material composition and material properties of the 301 spring tempered stainless steel. were listed in Table 5 and Table 6.

Table 5: Material Compositions

\begin{tabular}{|l|l|l|l|l|}
\hline Element & $\mathrm{C}$ & $\mathrm{Mn}$ & $\mathrm{Cr}$ & $\mathrm{Ni}$ \\
\hline Weight (\%) & $0.08-0.15$ & 2 & $16-18$ & $6-8$ \\
\hline
\end{tabular}

Table 6: Material Properties

\begin{tabular}{|l|c|}
\hline \multicolumn{2}{|c|}{ Physical Properties } \\
\hline Density (g/cc) & 8.03 \\
\hline \multicolumn{2}{|c|}{ Mechanical properties } \\
\hline Hardness Rockwell (Hrc) & 42 \\
\hline Ultimate Tensile Strength(MPa) & 1276 \\
\hline Bulk Modulus(GPa) & 70 \\
\hline Tensile Yield Strength(MPa) & 965 \\
\hline Elongation at Break (\%) & 9 \\
\hline Modulus of Elasticity(GPa) & 176 \\
\hline Poisson's Ratio & 0.33 \\
\hline Fatigue Strength(MPa) & 552 \\
\hline Machinability (\%) & 70 \\
\hline
\end{tabular}

\section{SUBSYSTEMS OF DEPLOYBLE MECHANISMS}

\section{Cubesat Deployer}

Interface plate: It will be in contact with both Cubesat and the compression spring.

NRCSD rail: NRCSD rails are provided to slide the Cubesat. Deployable switches are in contact with NRCSD 
rails until the Cubesat is inside the deployed. All subsystems are shown in figure 3

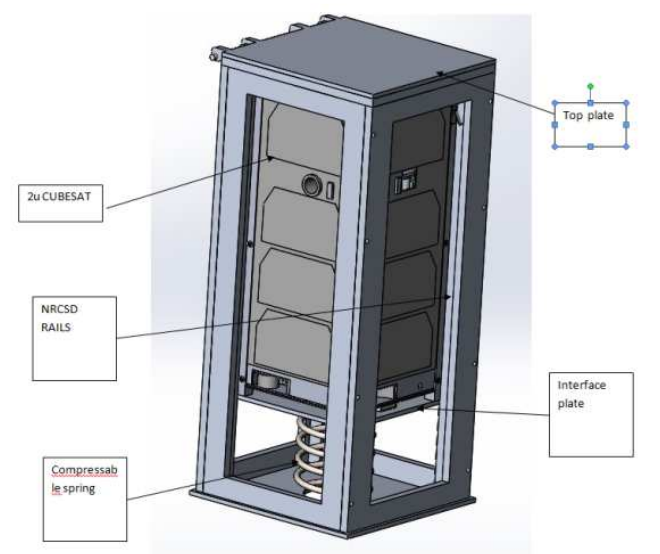

Figure 3: Subsystems in NRCSD

\section{Antenna Deployable Mechanism}

A combination that used in anus at-2 garment is 2 UHF, 2 VHF, 2 S-band monopole, one S-band patch and one GPS antenna. S-band patch antenna is placed side to the sun facing camera and GPS antenna is placed to lateral to s-band patch antenna, two s-band monopole antennas placed on opposite sides inside plates and UHF, VHF antennas were placed four sides as shown in figure 4

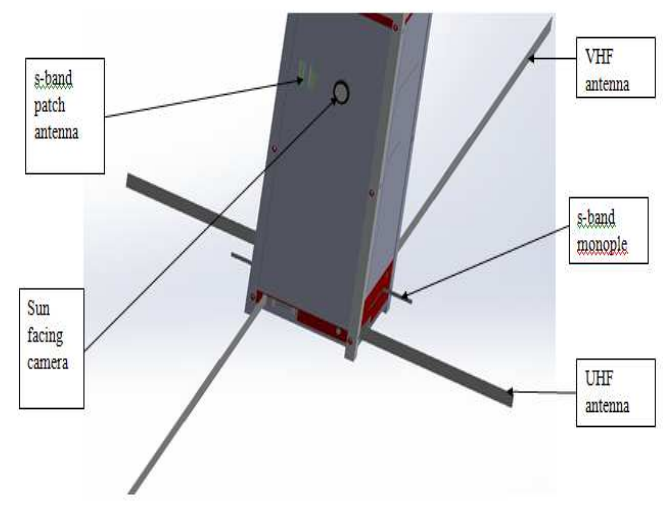

Figure 4: Subsystems, in Deployable Mechanism

\section{CONCEPTUAL DESIGN}

The length of an antenna is taken as the wavelength to frequency (300Mm/s / frequency in $\mathrm{MHz})$ with the answer in meters. This takes the wavelength as $300,000 \mathrm{Km} / \mathrm{s}$ (300 megameters/second).

For UHF, downlink frequency is $435 \mathrm{MHz}$ signal with a data rate of $9.6 \mathrm{Kbps}$.

So antenna length in meters $=300 / 435=0.689655$

Then it is divided by 4 for a quarter wavelength.

Therefore, antenna length $=0.689655 / 4=0.17241$ meters

For VHF, uplink frequency is $145 \mathrm{MHz}$ signal with data rate of $1.2 \mathrm{Kbps}$ 
Antenna length $=(300 /(145))=2.07$ meters.

Then it is divided by 4 for quarter wavelength.

Therefore, antenna length $=2.07 / 4=0.517241$ meters

Material - spring steel

Density $0.00803 \mathrm{~g} / \mathrm{mm} 3$

For UHF

Let DENSITY $(\mathrm{g} / \mathrm{mm} 3)=\operatorname{MASS}(\mathrm{g}) / \operatorname{VOLUME}(\mathrm{mm} 3)$

$0.00803=\mathrm{MASS} /(.1 * 9 * 172.41)$

MASS $=1.246$ grams

Considering 2 antennas, then total mass of antenna $=2.492$ grams

For VHF

Let DENSITY $(\mathrm{g} / \mathrm{mm} 3) \quad=\operatorname{MASS}(\mathrm{g}) / \operatorname{VOLUME}(\mathrm{mm} 3)$

$0.008456=$ MASS $/(0.1 * 9 * 517.241)$

MASS $=3.738$ grams

Considering 2 antennas, then total mass of antenna $=7.476$ grams.

No of turns to be rolled $=\mathrm{n}$

A diameter of the house is fixed to $15 \mathrm{~mm}$ due to space constraint in the bottom plate.An antenna has to be rolled within the $15 \mathrm{~mm}$ diameter.

Length of antenna $=\sum_{k=0}^{n} \Pi(\mathrm{D}-2 \mathrm{t}(\mathrm{K}))$

Where D -diameter of a house ( $\mathrm{mm})$

$\mathrm{t}$ the thickness of antenna $(\mathrm{mm})$.

For UHF antenna 12 turns give 524mm antenna length.

For VHF antenna 4 turns will give $183 \mathrm{~mm}$ length.

\section{CAD MODELLING ANTENNA DEPLOYABLE MECHANISM}

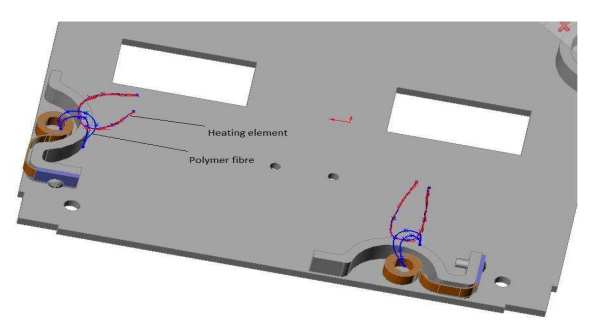

Figure 5: antenna Deployable Mechanism 
The antenna housings are assembled to the bottom plate. An Antenna of different lengths has been rolled and screwed into the antenna housings. Nylon wire is used for tightening the rolled antenna and nichrome wire is for melting the nylon wire at the time of ejection.The mechanism is as shown in figure 5.

On applying sufficient voltage to the nichrome wire it will get heated and melts the nylon wire. Due to the spring back effect of the antenna it will eject outwards to the required length.

\section{FEA ANALYSIS OF THE STRUCTURE}

\section{Structural Analysis}

Structural analysis may be broken down into two categories: Acceptance testing and Qualification tests.

- Acceptance testing is conducted on a finished, physical model of the flight-ready structure at $100 \%$ of the worst case loading scenario.

- Qualification testing is usually conducted using an engineering model and is performed at $150 \%$ of the worst case loading scenario. This results in a design safety factor of at least 1.5. The structure may be simulated using any of the FEM packages (ANSYS, ANSYS Workbench, Pro/E Mechanical, etc.)

\section{Applications of Loads}

The loads that the structure will experience during launch will be larger than any others experienced during its lifetime. It is therefore necessary to simulate the behavior of the structure during the takeoff of its launch vehicle. The loads that must be applied to the model during analysis will differ depending on the launch vehicle, and it is often difficult to know which vehicle will eventually be used in such an early stage of the design process.

\section{Quasi -Static Analysis}

The CAD model is meshed using four nod tetrahedral elements. The FEM model created is subject to the quasi static acceleration analysis by applying base acceleration of 10.8g. The FE analysis is performed in ANSYS WORKBENCH. The boundary conditions used in the analysis are shown in Figure 6.

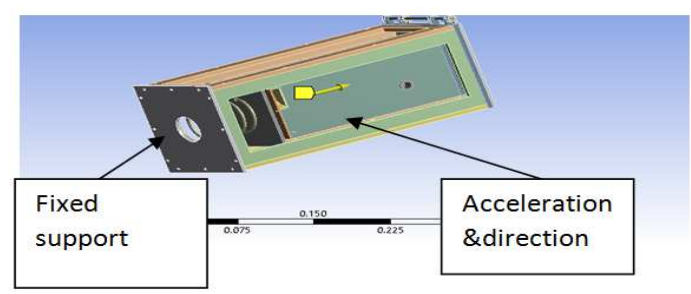

Figure 6: Boundary Conditions

\section{Inputs used}

Acceleration $=13 \mathrm{~g}$.

Mass of the deployer $=2 \mathrm{~kg}$

Factor of safety $=2$. 


\section{RESULTS}

The results obtained during analysis are shown in following Figures 7, 8 \& 9.

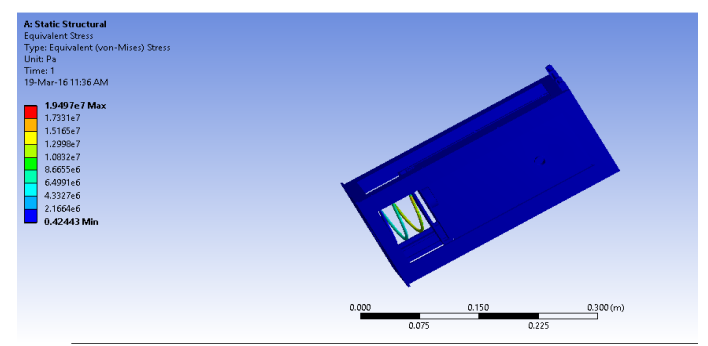

Figure 7: Von-mises Stress

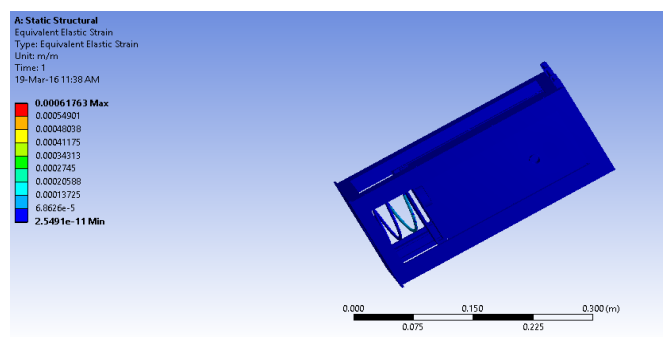

Figure 8: Von-mises Strain

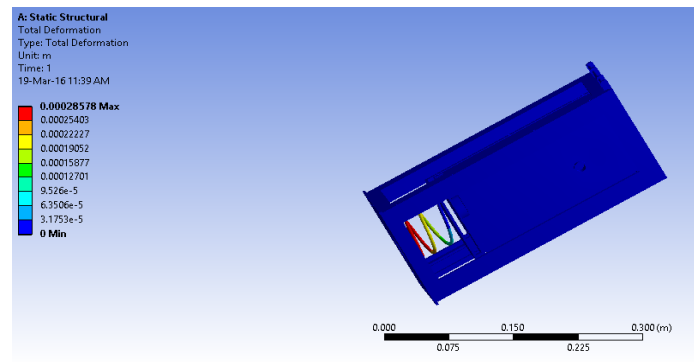

Figure 9: Total Deformation

After each analysis, the maximum Von Mises stresses observed in each part of the model are compared with the yield limit of the different material selected for each part. The Margin of Safety (MOS) is calculated using the following formulae.

$$
\operatorname{MOS}=\frac{\sigma y}{\sigma l o a d}-1
$$

Where,

$\sigma y$ is the yield strength of the material,

oload is the maximum Von Mises equivalent stress due to acceleration loads.

It could be observed from the obtained results that the maximum deformation is only $10.46 \mu \mathrm{m}$ (spring) and the minimum MOS is 10 (spring). In view of very few deformation and high MOS, it could be concluded that the NRCSD meets the QB50 system requirement for acceleration load.

\section{Resonance Survey}

The Natural frequency of the Cubesat deployed at that exerted at the time of launching is $90 \mathrm{~Hz}$. 


\section{Boundary Conditions}

Feet near the Fipex are fixed. In the P-POD, the feet of the satellite are in contact with either the bottom or the top of the structure, or with the feet of adjacent CubeSats. Therefore, the boundary condition applied to the feet is simply a locking along the $\mathrm{Z}$ direction. On applying the boundary conditions the modal analysis is performed.

\section{Mode Shapes}

The mode shapes obtained during analysis are shown in the following figures.

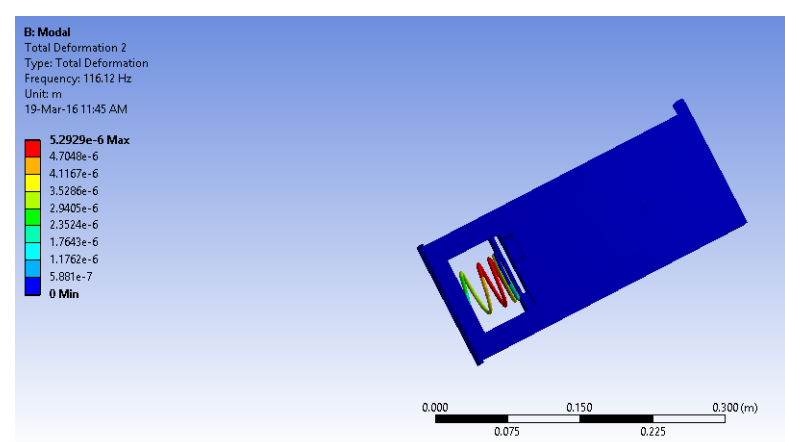

Mode 1: 116.12 Hz

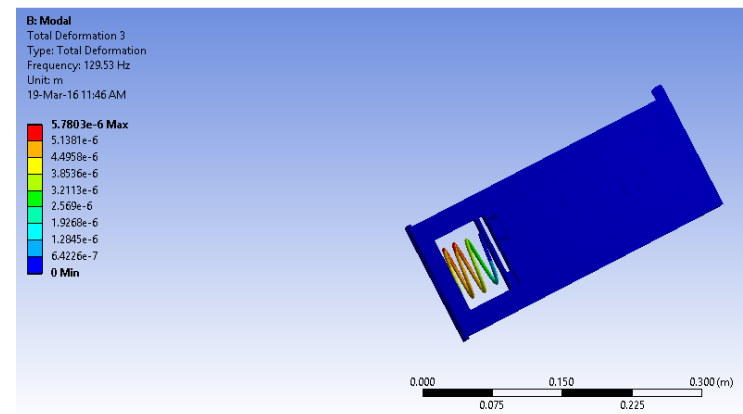

Mode 2: $129.53 \mathrm{~Hz}$

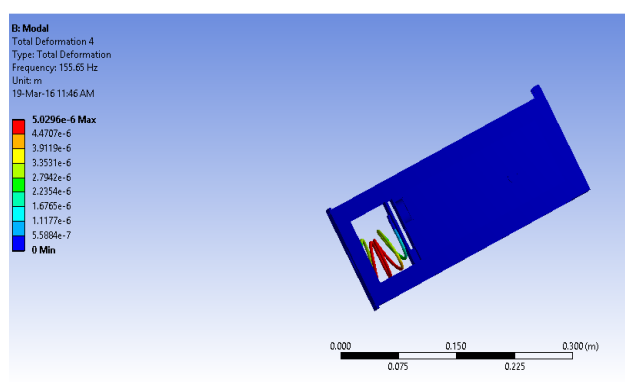

Mode 3: 155.65 


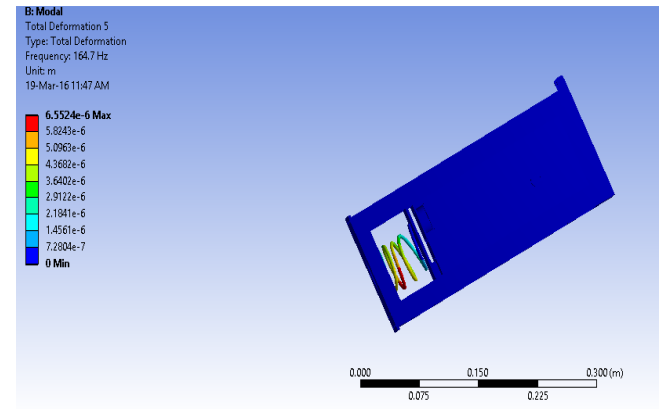

Mode 4: 164.7

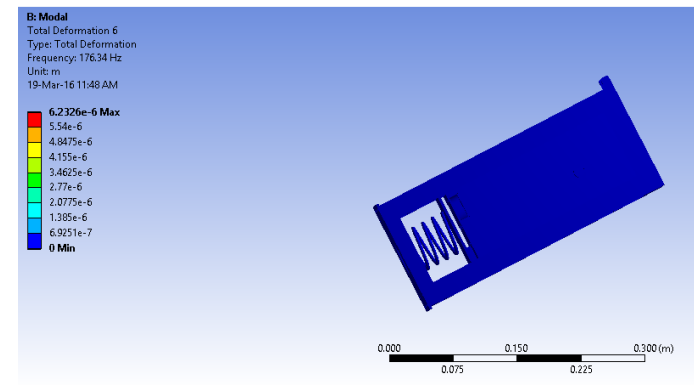

Mode 5: 176.34

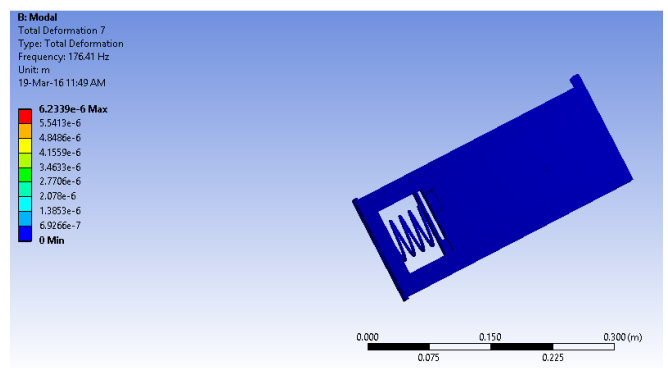

Mode 6: 176.41

Figure 10: Shapes of Successive Modes

The six first flexible modes are listed in Table VI with their frequencies and a short description of their mode shapes.

Table 6: Modes with Frequency and Description

\begin{tabular}{|c|c|l|c|}
\hline Mode & Frequency $[\mathrm{Hz}]$ & \multicolumn{1}{|c|}{ Description } & Max Deformation $(\boldsymbol{\mu m})$ \\
\hline 1 & 116.12 & Bending of the spring board along Y axis & 5.29 \\
\hline 2 & 129.53 & Bending of the spring board along X axis & 5.78 \\
\hline 3 & 155.65 & Out of plane bending of spring on XY plane & 5.02 \\
\hline 4 & 164.7 & Bending of the spring along X axis & 6.52 \\
\hline 5 & 174.34 & Bending of the interface plate Y axis & 6.23 \\
\hline 6 & 174.41 & Asymmetry bending of spring & 6.23 \\
\hline
\end{tabular}

From the above table, it is observed that the first natural frequency is $116.26 \mathrm{~Hz}$, which is well greater than $90 \mathrm{~Hz}$ and the maximum deformation is $6.52 \mu \mathrm{m}$. Hence, the model meets the requirements of resonance survey.

\section{CONCLUSIONS}

The first chapter of this report gives a general introduction of cubesat. Second and third chapter exposed a general 
introduction of deployable mechanisms, design constraints, and methodology of mechanism design. Then, a static analysis was performed, and the results obtained ensured that it withstands well the quasi-static loads which will be applied to it during the launch phase. The modal analysis led also to results that fulfill all QB50 requirements.

Fabrication of cube deployer, antenna deployable mechanism and experimental analysis of deployer structure are needed to be done in future.

\section{REFERENCES}

1. YoshikiSugawara, ShinichiNakasuka, KenjiHigashi, ChisatoKobayashi, Kanichi Koyama and TakanoriOkada 2009 'Structure and thermal control of panel extension satellite (PETSAT)' Journal of ActaAstronautica, vol.65 (2009), pp. 958-966

2. Gauthier pierlot 2009 ouftil flight system configuration and structural analysis master thesis paper in Aerospace Engineering, University of liege pp. $49-88$

3. Jose Miguel Encinas Plaza, Jose Antonio VilánVilán, Fernando AguadoAgelet, Javier BarandiaránMancheño, Miguel LópezEstévez, Cesar MartínezFernández and Fany Sarmiento Ares 2010 Xatcobeo: Small Mechanisms for CubeSat Satellites - Antenna and Solar Array Deployment journal of 40th Aerospace Mechanisms Symposium, NASA Kennedy Space Center pp. $01-16$.

4. JordiPuig-Suari, Clark Turner, William Ahlgren(2010) Development of the Standard CubeSat Deployer and a CubeSat Class PicoSatellite, thesis for California state university.

5. G. Fanchini, D. Gagliostro 2011 The e-st@ $@$ CubeSat:Antennassystems Journal of ActaAstronautica, pp. 1089 -1095

6. MajaSkiljo and ZoranBlazevic 2011 Helical Antennas in Satellite Radio channel, Advances in Satellite Communications pp. 01 $-25$

7. Fiona Singarayar 2012 Preliminary System Development and Detailed Structural Design and Analysis for the CanX-7 Nanosatellite thesis for Master of Applied Science pp. 24 - 74

8. Alessandra Babusciaa, n, Benjamin Corbina, Mary Knappa, Rebecca Jensen-Clemb, MarkVande Loo a, Sara Seager 2013 'Inflatable antenna for cubesats : Motivation for development and antenna design Journal of ActaAstronautica, pp. 01 -11.

9. Marcin Dobrowolski, Jerzy Grygorczuk, Bartosz Kędziora, Marta Tokarz and Maciej Borys 2014 DRAGON - 8U Nanosatellite Orbital Deployer 
